\title{
Challenge Agent Category
}

National Cancer Institute

\section{Source}

National Cancer Institute. Challenge Agent Category. NCI Thesaurus. Code C158298.

A general classification of the challenge agent used in the study model. 